\title{
Fatigue and overstress indicators for ultra-light and light aircraft
}

\author{
Tetiana Maslak ${ }^{1}$, Mikhail Karuskevich ${ }^{1}$, Sergey Ignatovich ${ }^{1}$, Oleg Karuskevich ${ }^{1}$, Łukasz \\ Pejkowski $^{2}$, and Pavol Kurdel ${ }^{3}$ \\ ${ }^{1}$ National Aviation University \\ ${ }^{2}$ Uniwersytet Technologiczno-Przyrodniczy im Jana i Jedrzeja Sniadeckich w Bydgoszczy \\ ${ }^{3}$ Technical University of Košice Faculty of Aeronautics
}

September 28, 2020

\begin{abstract}
The paper deals with the problem of ultra-light and light aircraft structural health monitoring. The phenomenological basis and engineering decisions for methods to monitor accumulated fatigue damage and to register overstress of aircraft principal structural elements have been shown. The proposed fatigue indicator is lightweight and autonomous; the output information of the indicator reflects the inhering feature of the fatigue damage - appearance and growth of surface extrusions and intrusions. The overstress indicator simplicity and correctness of the information is provided by "fuse" principle of the design.
\end{abstract}

\section{Fatigue and overstress indicators for ultra-light and light aircraft}

\section{Karuskevich ${ }^{1}$, S.Ignatovich ${ }^{1}$, O.Karuskevich $^{1}$, T.Maslak $^{1, *}$, Ł.Pejkowski $^{2}$, P. Kurdel $^{3}$}

${ }^{1}$ National Aviation University, Liubomyra Huzara ave. 1, Kyiv 03058, Ukraine

${ }^{2}$ University of Science and Technology, S. Kaliskiego 7, 85-796 Bydgoszcz, Poland

${ }^{3}$ Technical University of Košice, Rampová 7, 04121 Košice, Slovakia

\section{Introduction}

Certification specifications for Light Sport Aeroplanes (CS-LSA) define the strength requirements for the Light Sport aircraft and confirm the importance of the fatigue analysis [1].

The trend currently exists to monitor metal fatigue by Structural Health Monitoring Systems. This approach is on the way to be implemented into contemporary large planes. There are many reasons to use fatigue monitoring for small planes as well. Taking into account the limitation of the weight for this category of aircraft, the described here miniature autonomous fatigue indicator looks a prospective alternative to the complex monitoring systems.

Another problem of light planes is an operational overstress of principal structural elements. Sometimes these planes are not equipped with an accelerometer. Overstress of the plane components due to the incorrect flight regime can lead to the primary structure deformation, and even to the aircraft crash.

One fatal accident [2] with Cessna 210L Centurion was investigated but the final precise decision regarding the cause of the aircraft fracture was not made. The presence of the overstress indicator would clarify the situation and develop some recommendations for pilots and engineers.

\section{Small aircraft fatigue}


Like any aircraft, the LSA are subjected to a wide spectrum of operational loads. The level of allowed acceleration for the LSA is higher than for the planes of transport category: the maximum positive load factor prescribed, for example for the Viper SD-4 [3] is equal to $+4.0 \mathrm{~g}$, the minimum is $-2.0 \mathrm{~g}$.

As a proof of the necessity of the special attention to the metal fatigue for small aircraft the fatigue damage case study of the Piper aeroplane primary structure may be considered. During a routine inspection of a Piper Model PA-46-350P aeroplane, 1.53-inch () fatigue crack was discovered in the main spar lower cap (Fig.1). The crack discovery was at 5,273-hour time-in-service (TIS) versus the type certificated life limit of 15,580 hours TIS [4].

The list of fatigue issues could be extended, but even these examples prove the requirements for the special attention for the aircraft primary structure fatigue.

\section{Fatigue monitoring}

The methods for fatigue monitoring for the Light Aircraft must differ from the systems which can be developed for and used on large transport planes. The indicator must be an autonomous, self-data-registering unit, miniature and lightweight.

All these requirements meets the Surface Relief Fatigue Indicator (SRFI).

Fatigue process for some metals is accompanied by formation and evolution of the surface deformation relief - the pattern of surface extrusion, intrusion, persistent slip bands (Fig. 1) [5]. The deformation relief is a three-dimensional structure.

The pure aluminium due to its plasticity react on deformation by the exhibiting surface relief. Pure aluminium is not used as constructional material, but it is often used for the protection of aluminium alloys against corrosion being clad layer of so- called Al-Clad aluminium alloy. The 2024-T3, 7075-T6 are well known examples of Al-Clad alloys used in the aviation industry.

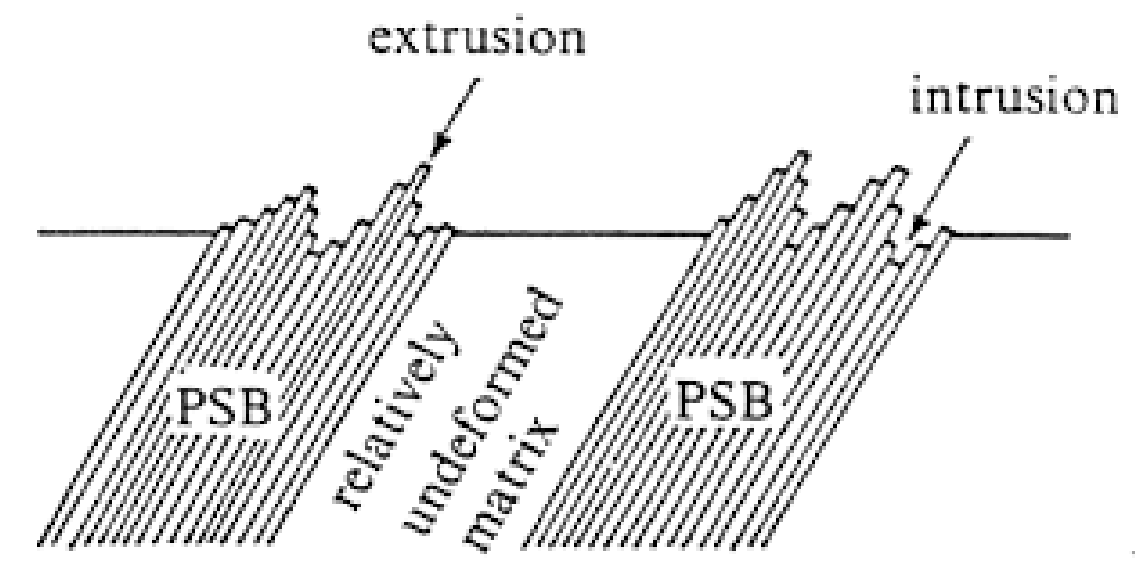

Fig. 1. Surface relief extrusion/intrusion pattern scheme [5]

The relief parameters were proposed and verified by the numerous experiments [6-9].

The primary damage parameter considers the intensity of the surface relief:

where: $S_{\text {deform. relief - surface area with deformation relief; } \mathrm{S}_{\text {total }} \text { - total investigated area. }}$

The additional damage parameter is a fractal dimension of the surface pattern. It describes quantitatively the shape of surface relief clusters. The fractal dimension $\mathrm{Dp} / \mathrm{s}$ is based on the ratio of the perimeter of the 
clusters to their area:

where: $N \pi(\delta), N \sigma(\delta)$ - number of cells with the size $\delta$ in pixels, which cover the perimeter and area of deformation relief clusters.

It was proved, that the remaining life of the component, made of a metal exhibiting surface relief could be calculated with an empirical relationship between the number of cycles to failure and relief parameters:

$\mathrm{N}_{\text {remaining }}=\mathrm{f}(\mathrm{D}, \mathrm{Dp} / \mathrm{s})$.

Some bearing components of the primary structure are not able to exhibit surface relief after cyclical loading due to their physical properties, that's why the attachable fatigue indicator has been proposed as an alternative to the direct investigation of the surface of the components.

Indicator (sensor) looks like a micro specimen for fatigue tests (Fig. 2) made of Al-clad alloy.

The strain of the indicator is not constant value along the indicator axis; it depends on the stiffness, which varies due to the different cross sections. The required level of strain and stress in the inspected cross section of the indicator can be achieved by the proper selection of the indicator's geometry. This procedure is provided by the application of Finite Elements Analysis (FEA) using ANSYS software.

\section{Hosted file}

image4.emf available at https://authorea.com/users/361817/articles/483133-fatigue-andoverstress-indicators-for-ultra-light-and-light-aircraft

Fig. 2. Fatigue indicator dimensions

Whilst the task for sensitivity increase looks realistic by manipulation with geometry, the problem of buckling prevention introduces limitations on the indicator practical use.

The problem is that some aircraft components, for example, wing, work under both the compression and tension. This situation causes limitations on the indicator geometry. The buckling analysis has been conducted by two methods: a) following the classic Euler's formula for critical load; b) using eigenvalue buckling analysis in ANSYS software (Fig.3).

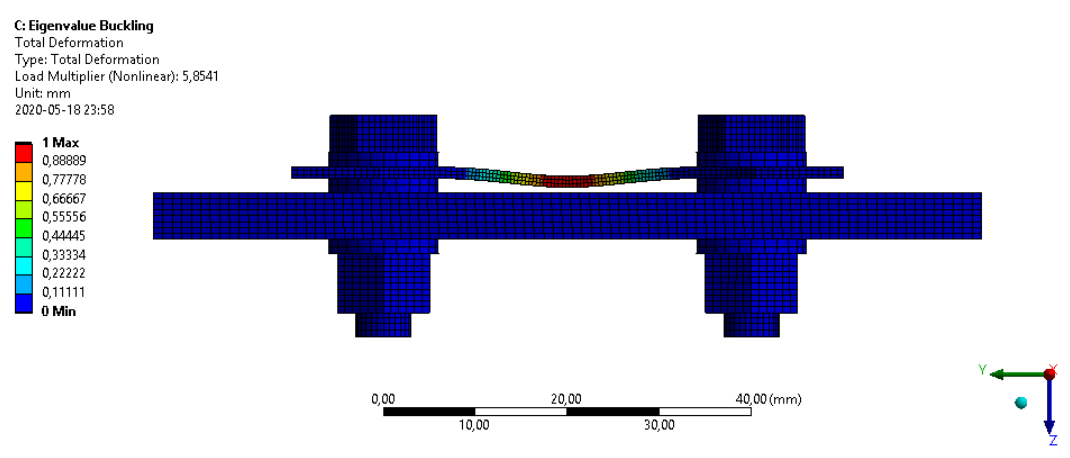

Fig. 3. ANSYS buckling simulation

It was proved by the ANSYS buckling simulation that the danger of the stability loss doesn't exist at the realistic spectrum of loads on aircraft wing.

The sensitivity of the deformation relief evolution to the stress level can be illustrated by results of surface relief monitoring for three sensors of different sensitivity (Fig.4). The structural elements with sensors were loaded by cycle with $=157 \mathrm{MPa}, R=0$. 


\section{Hosted file}

image7.emf available at https://authorea.com/users/361817/articles/483133-fatigue-andoverstress-indicators-for-ultra-light-and-light-aircraft

$\mathrm{N}$, thousands cycles

Fig. 4. Damage accumulation for three indicators of different sensitivity: 1 - indicator with local stress 280 MPa; 2 - indicator with local stress $260 \mathrm{MPa} ; 3$ - indicator with local stress $240 \mathrm{MPa}$

\section{Overstress Indicator for Ultra-Light and Light Airplanes}

The practice of the fuses and mechanical safeguards application in the engineering structures and mechanisms for prevention of over regular regimes. Different types of safeguard devices are successfully used in the different fields of technics to prevent failure of the machines, equipment, and systems.

Design of proposed Overstress Indicator resembles the described above fatigue sensor. Whilst the fatigue indicator reacts to repeating loads by the evolution of the sensor's surface state, the overstress indicator reacts excessive strain by its complete failure. Similar to the fatigue sensor, the sensitivity of the indicator depends on the geometry: necked working section has higher strain than any others indicator's section.

Transmitting overstress indicator's signal into the cabin doesn't require very much sophisticated arrangement. The onboard system of relays can be used to supply information regarding the state of the indicator.

\section{Conclusion}

Fatigue and overstress of the principal structural element are crucial problems for all categories of aircraft. Light and Ultra-Light aircraft have limited opportunities for the application of advanced Structural Health Monitoring Systems. That is why the autonomous Surface Relief Fatigue Indicator (SRFI) may be considered as a reliable tool for the fatigue monitoring.

Light and Ultra-Light due to the action of the unallowable accelerations in manoeuvers meet the overstress conditions for the components. The excessive stresses can lead to the deformation of the structure, loss of the aerodynamic characteristics and even to an aircraft crash. The overstress can be revealed by the simple proposed device, called here Overstress Indicator. It allows for prevention flight with damaged structure, thus increases the safety of the operation.

\section{References}

1. Easy Access Rules for Light Sport Aeroplanes (CS-LSA) (Amendment 1), EASA Rules Nov. 2018. P.24.

2. https://bst-tsb.gc.ca/eng/rapports-reports/aviation/2001/a01o0165/a01o0165.html

3. http://tomarkaero.com/en/

4. http://www.aero-news.net/index.cfm?do=main.textpostEid=7ba6dcbb-aeb7-41b2-a8e1-3754e6ff94b9

5. https://fcp.mechse.illinois.edu/files/2014/07/02_fundamentals.pdf

6. M. Karuskevich, O. Karuskevich, T. Maslak, S. Schepak, Int J Fatigue 39, 116-121(2012).

7. M. Karuskevych, I. Zhuravel', T. Maslak, Materials Science 47, 621-626 (2012).

8. M. Karuskevich, S. Ignatovich, M. Petrasek, T. Maslak Advances in military technology 8, 83-91(2013).

9. Ł. Pejkowski, M. Karuskevich, T. Maslak Extrusion/intrusion structure as a fatigue indicator for uniaxial and multiaxial loading. Fatigue Fract Eng Mater Struct. - 2019. - Volume 42. Issue 10 P.2315-2324.

\section{Hosted file}

Statement of contribution.pdf available at https://authorea.com/users/361817/articles/483133fatigue-and-overstress-indicators-for-ultra-light-and-light-aircraft 